\title{
Correction to: AIDS Patient Care and STDs 2016;30:425-434; DOI: 10.1089/apc.2016.0114
}

In the article, "Good Health and Moral Responsibility: Key Concepts Underlying the Interpretation of Treatment as Prevention in South Africa and Zambia Before Rolling Out Universal HIV Testing and Treatment," published in AIDS Patient Care and STDs 2016;30:425-434, there was an error in the author line. This article was based on research conducted as part of a community randomized trial called HPTN071/PopART. To acknowledge the contribution made by this large and diverse group, the intent was to include the HPTN071 (PopART) Study Team on the author line, but the group was inadvertently omitted. The author line should read as follows:

Virginia Bond, MA (Hons), PhD, ${ }^{1,2}$ Graeme Hoddinott, MSocSci, ${ }^{3}$ Lario Viljoen, MA, Melvin Simuyaba, BSW, Maurice Musheke, MPH, PhD, and Janet Seeley, MPhil, PhD, ${ }^{1,4}$ on behalf of the HPTN071 (PopART) Study Team

The online version of the article has been corrected to reflect this change. The authors regret this error. 